\title{
Improved restoration of thoracic kyphosis using a rod construct with differentiated rigidity in the surgical treatment of adolescent idiopathic scoliosis
}

\author{
Søren Ohrt-Nissen, MD, ${ }^{1}$ Casper Dragsted, MD, ${ }^{1}$ Benny Dahl, MD, DMSc, ${ }^{2}$ \\ John A. I. Ferguson, MBChB, FRACS,$^{3}$ and Martin Gehrchen, MD, PhD'
}

${ }^{1}$ Department of Orthopaedic Surgery, Spine Unit, University Hospital of Copenhagen, Denmark; ${ }^{2}$ Department of Orthopedics and Scoliosis Surgery, Texas Children's Hospital, Houston, Texas; and 'Starship Children's Hospital, Grafton, Auckland, New Zealand

OBJECTIVE The objective of this study was to compare postoperative sagittal alignment among 3 rod constructs with different rigidity profiles.

METHODS This was a dual-center retrospective cohort study involving 2 consecutive cohorts in which patients were surgically treated for adolescent idiopathic scoliosis. Lenke Type 5 curves were excluded. Patients were operated on with all-pedicle screw instrumentation using 3 different rod constructs. The first group was operated on using a hybrid construct $(\mathrm{HC})$ consisting of a normal circular rod on the convex side and a beam-like rod (BR) on the concave side. The second group was operated on with a standard construct (SC) using bilateral BRs in the full length of the fusion. The third group was operated on with a modified construct (MC). The modified rods have a beam-like shape in the caudal portion, but in the cranial 2 or 3 fusion levels the rod transitions to a circular shape with a smaller anteroposterior diameter. Radiographs were analyzed preoperatively and at the first postoperative follow-up (range 1-8 weeks). The primary outcome was pre- to postoperative change in thoracic kyphosis (TK), and the secondary outcome was the ability to achieve postoperative TK within the normal range.

RESULTS The HC, SC, and MC groups included 23,70 , and 46 patients, respectively. The 3 groups did not differ significantly in preoperative demographic or radiographic parameters. The mean \pm standard deviation of the preoperative main curve was $60.7^{\circ} \pm 12.6^{\circ}$, and the mean of curve correction was $62.9 \% \pm 10.4 \%$ with no significant difference among groups $(p \geq 0.680)$. The groups did not differ significantly in coronal balance or proximal or thoracolumbar curve correction ( $p \geq 0.189$ ). Mean postoperative TK was $23.1^{\circ} \pm 6.3^{\circ}, 19.6^{\circ} \pm 7.6^{\circ}$, and $23.4^{\circ} \pm 6.9^{\circ}$ in the $\mathrm{HC}, \mathrm{SC}$ and $\mathrm{MC}$ groups, respectively $(p=0.013)$, and the mean change in TK was $-3.5^{\circ} \pm 11.3^{\circ},-7.1^{\circ} \pm 11.6^{\circ}$, and $0.1^{\circ} \pm 10.9^{\circ}$, respectively $(p=0.005)$. The MC group had significantly higher postoperative TK and less loss of TK compared with the SC group $(p \leq 0.018)$. Postoperative TK $\leq 10^{\circ}$ was found in 12 patients $(17 \%)$ in the SC group, 1 patient $(5 \%)$ in the $\mathrm{HC}$ group, and 1 patient $(2 \%)$ in the MC group $(p=0.021)$. There were no differences in proximal alignment, thoracolumbar alignment, or sagittal vertical axis $(p \geq 0.249)$. Lumbar lordosis was $58.9^{\circ} \pm 11.2^{\circ}$ in the $\mathrm{HC}$ group versus $52.0^{\circ} \pm 1.3^{\circ}$ and $55.0^{\circ} \pm 11.0^{\circ}$ and the $S C$ and MC groups, respectively $(p=0.040)$.

CONCLUSIONS In the 3 rod constructs with different rigidity profiles, significantly better restoration of kyphosis was achieved with the use of bilateral modified rods compared with bilateral standard rods. In the MC and $\mathrm{HC}$ groups, the rate of severe postoperative hypokyphosis was significantly lower than in the SC group. This is the first study to describe the clinical use of a rod with a reduced proximal diameter and show marked radiographic improvement in sagittal alignment.

https://thejns.org/doi/abs/10.3171/2017.7.FOCUS17351

KEY WORDS rod; rigidity; adolescent idiopathic scoliosis; thoracic kyphosis; sagittal alignment; construct; instrumentation 
$\mathrm{T}$ he main purpose of the surgical treatment of adolescent idiopathic scoliosis (AIS) is to achieve a stable deformity correction while ensuring a balanced spine in the coronal and sagittal planes. ${ }^{10}$ Coronal deformity correction has improved substantially with the introduction of all-pedicle screw (PS) constructs, which largely have replaced hook-based instrumentation in modern AIS surgery. ${ }^{9,21,33,38}$ Numerous studies have confirmed that coronal and axial curve correction with PS instrumentation is substantial with minimal loss of correction at midand long-term follow-ups, resulting in significant improvement in the quality of life for the patient. ${ }^{13,15,31,35}$ However, to achieve a balanced spine in the $3 \mathrm{D}$ plane, normal sagittal balance should be the goal. AIS patients typically have relative preoperative lordosis of the thoracic spine (i.e., hypokyphosis) that should be addressed intraoperatively, ${ }^{29}$ but several studies have shown that PS constructs are not efficient in restoring thoracic kyphosis (TK) to a normal range. ${ }^{25,38}$ The reason for this is not fully understood but is believed to be associated with intraoperative correction techniques and the biochemical properties of the rods. ${ }^{1,5,11}$ Various rod insertion techniques have been described to optimize 3D correction, including derotation, cantilever reduction, translation, and in situ rod bending, but none of these have shown a consistent positive effect on sagittal alignment. ${ }^{7,17,27,37}$

Recently, a study assessed the effect of increasing rod strength by introducing bilateral beam-like rods (BRs), which have a larger anteroposterior (AP) diameter than traditional circular rods (Fig. 1). This resulted in improved coronal curve correction, but a loss of TK was observed postoperatively. ${ }^{12}$ The $3 \mathrm{D}$ effects of increasing rod rigidity have not been firmly established, and we hypothesize that increasing the strength of the rod may have a negative effect on the sagittal profile as it can be technically challenging to achieve sufficient kyphosis of the rod while ensuring correct rod insertion and at the same time correcting the coronal deformity. A recent study, using a computerized model, showed that the use of rods with a small-diameter transition at the most cranial level results in decreased stress at the proximal junction, which may have an effect on the sagittal profile in a clinical setting. ${ }^{4}$

Achieving optimal sagittal alignment should be a key objective of surgery as postoperative hypokyphosis is unsatisfactory to the patient and may affect the patient's long-term quality of life. ${ }^{11,14}$ As such, the aim of the current study was to compare postoperative sagittal alignment among 3 rod constructs with different rigidity profiles.

\section{Methods}

The current study was a dual-center retrospective cohort study. Two consecutive cohorts that were surgically treated for AIS between September 2012 and October 2016 were included. The inclusion criteria were a diagnosis of AIS and a structural main thoracic curve (Lenke Type I, II, III, IV, and VI) ${ }^{23}$ and all-PS instrumentation of the main thoracic curve. A subset of the population was previously described. ${ }^{12}$ This study was approved by the local data protection agency and patient safety authority.

\section{Surgical Technique}

All patients were operated on through a posterior midline approach with no adjuvant anterior release. Surgical correction involved facetectomies at all levels intended for fusion, and segmental uniplanar low-profile pedicle screws were used for fixation. Differential rod contouring with rod derotation was performed, and direct vertebral rotation was applied when deemed necessary. Ponte osteotomies at the apex were not used routinely except in stiff curves evaluated intraoperatively by the surgeon. Patients were divided into 3 groups: The first group was operated on using a hybrid construct (HC) consisting of a normal circular rod on the convex side of the main curvature and a standard BR on the concave side. The second group was operated with a standard construct (SC) using bilateral BRs in the full length of the fusion. The third group was operated with a modified construct (MC). For the MC, the rods have a beam-like shape in the caudal portion, but in the cranial 2 or 3 fusion levels the rod transitions to a circular shape with a smaller AP diameter $(5.5 \mathrm{~mm})$ (Fig. 1). This design is believed to allow more reliable cranial contouring of the rod and less junctional stress, thus augmenting kyphosis, but this has never been examined in a clinical setting.

\section{Radiographic Analysis}

All images were uploaded to the same radiographic software (KEOPS, SMAIO), and radiographic measurements were done by 1 investigator (C.D.) with extensive experience in diagnosis of pediatric deformities. Radiographs were analyzed preoperatively and at the first postoperative follow-up, which was within the first 6 weeks after surgery. From the standing AP radiograph, the following variables were measured: the Cobb angles of the main thoracic curve, proximal thoracic curve, and thoracolumbar curve, translation of the apical vertebra, and coronal balance (the horizontal distance from the C-7 plumb line to the central sacral vertical line). On the standing lateral radiograph, the following variables were measured: TK (T5-12), lumbar lordosis (L1-S1), proximal sagittal alignment (T2-5), thoracolumbar sagittal alignment (T10-L2), and sagittal vertical axis. The Cobb angle of the main curve was measured on the preoperative supine lateral-bending radiograph. Additional variables included the curve type according to Lenke et al., ${ }^{23}$ number of vertebrae in the main curve, and number of fused segments. Additionally, preoperative flexibility and postoperative curve correction were calculated.

\section{Statistical Analysis}

The primary outcome was pre- to postoperative change in TK, and the secondary outcome was the ability to achieve postoperative TK within the normal range. All statistical analyses were performed using R (version 3.3.1; $\mathrm{R}$ Core Team). Data are presented as the percentage, mean \pm standard deviation, or median with interquartile range. Data distributions were assessed with histograms, and either the chi-square test or Fisher's test was used to analyze categorical data. Parametric data were compared using the Kruskal-Wallis test or ANOVA. Post hoc analysis was 

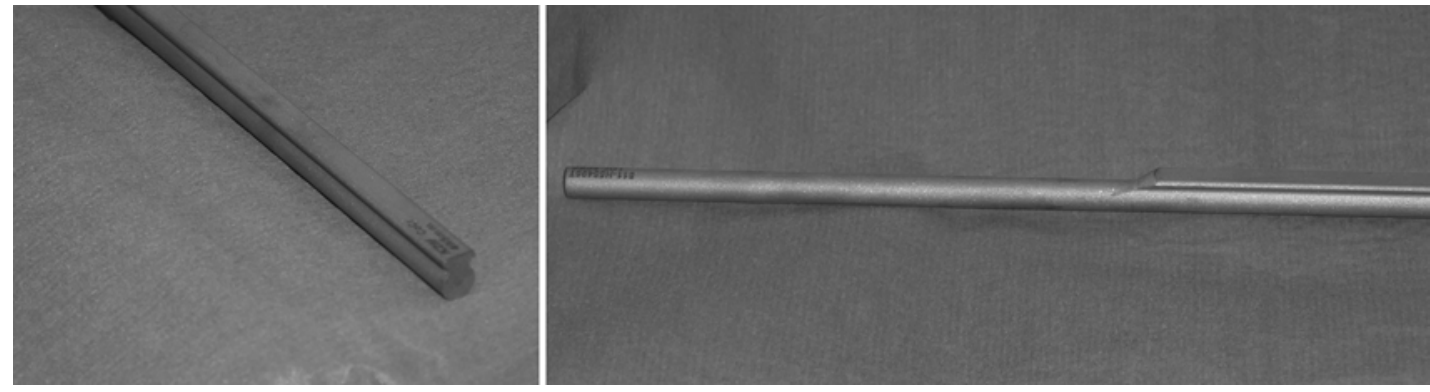

FIG. 1. Left: Standard beam-like rod. Right: Modified rod with a beam-like shape in the caudal portion. In the cranial 3 fusion levels, the rod transitions to a circular shape with a smaller AP diameter.

performed in cases of significant difference using Tukey's post hoc test. A p value of less than 0.05 was considered statistically significant.

\section{Results}

A total of 141 patients met the inclusion criteria. Two patients were excluded because of insufficient radiographic data, leaving 139 patients for the final analysis. The $\mathrm{HC}$ group consisted of 23 patients who were all surgically treated by the same surgeon, while the SC and MC groups consisted of 70 and 46 patients, respectively. These patients were operated on in a consecutive manner (SC group followed by MC group) at the same facility by 1 of 5 experienced staff surgeons. All rods were 5.5-mm cobaltchrome rods, except in the cases of 3 patients in the HC cohort in whom 4.5-mm cobalt-chrome rods were used.

The 3 groups did not differ in terms of sex or Lenke curve distribution $(\mathrm{p} \geq 0.118)$ (Table 1$)$. The mean preoperative main curve was $60.7^{\circ} \pm 12.6^{\circ}$, and the mean curve correction was $62.9 \% \pm 10.4 \%$ with no significant difference among groups $(\mathrm{p} \geq 0.680)$ (Table 2 and Fig. 2). The groups did not differ significantly in terms of coronal bal-

TABLE 1. Baseline clinical and radiographic variables

\begin{tabular}{|c|c|c|c|c|}
\hline \multirow[b]{2}{*}{ Variable } & \multicolumn{3}{|c|}{ Construct Group } & \multirow[b]{2}{*}{ p Value } \\
\hline & $\mathrm{HC}$ & SC & MC & \\
\hline No. of patients & 23 & 70 & 46 & \\
\hline \multicolumn{5}{|l|}{ Sex, no. $(\%)$} \\
\hline Female & $20(87)$ & $57(81)$ & $40(87)$ & \\
\hline Male & $3(13)$ & $13(19)$ & $6(13)$ & 0.776 \\
\hline \multicolumn{5}{|l|}{ Lenke type, no. (\%) } \\
\hline 1 & $19(83)$ & $40(57)$ & $29(63)$ & \\
\hline 2 & $1(4)$ & $15(21)$ & $7(15)$ & \\
\hline 3 & $2(9)$ & $3(4)$ & $5(11)$ & \\
\hline 4 & $1(4)$ & $4(6)$ & $0(0)$ & \\
\hline 6 & $0(0)$ & $8(11)$ & $5(11)$ & 0.118 \\
\hline No. of vertebrae in main curve, median (IQR) & $7(7-8)$ & $7(6-8)$ & $7.0(7-8)$ & 0.598 \\
\hline No. of vertebrae in fusion, median (IQR) & $12(11-13)$ & $11(10-12)$ & $11(10-12)$ & 0.158 \\
\hline Main curve, ${ }^{\circ}$ & $60.1 \pm 15.5$ & $62.2 \pm 12.7$ & $58.8 \pm 10.4$ & 0.355 \\
\hline Flexibility of main curve, $\%$ & $39.7 \pm 16.7$ & $40.7 \pm 16.2$ & $38.7 \pm 14.0$ & 0.802 \\
\hline Translation of main curve, $\mathrm{cm}$ & $5.3 \pm 3.1$ & $6.4 \pm 3.0$ & $6.0 \pm 25.0$ & 0.334 \\
\hline Proximal curve, $^{\circ}$ & $35.5 \pm 11.0$ & $37.8 \pm 10.8$ & $36.8 \pm 10.8$ & 0.682 \\
\hline Thoracolumbar/lumbar curve, $^{\circ}$ & $28.2 \pm 10.5$ & $31.8 \pm 12.1$ & $31.5 \pm 10.8$ & 0.444 \\
\hline Coronal balance, median (IQR), $\mathrm{cm}^{*}$ & $1.7(0.9-2.7)$ & $1.8(0-2.7)$ & $1.2(0.5-2.1)$ & 0.965 \\
\hline TK, ${ }^{\circ}$ & $26.6 \pm 13.8$ & $26.2 \pm 12.8$ & $23.7 \pm 12.7$ & 0.430 \\
\hline Proximal alignment at T2-5, & $14.3 \pm 6.8$ & $12.4 \pm 6.4$ & $13.4 \pm 6.8$ & 0.463 \\
\hline Thoracolumbar alignment at T10-L2, ${ }^{\circ}$ & $7.7 \pm 8.5$ & $9.4 \pm 6.8$ & $10.7 \pm 6.2$ & 0.249 \\
\hline Lumbar lordosis, $^{\circ}$ & $65.4 \pm 10.3$ & $58.9 \pm 11.1$ & $61.0 \pm 12.0$ & 0.067 \\
\hline Sagittal vertical axis, median (IQR), $\mathrm{cm}^{*}$ & $2.8(1.4-5.4)$ & $3.4(2.0-5.6)$ & $3.2(1.6-4.4)$ & 0.459 \\
\hline
\end{tabular}


TABLE 2. Postoperative radiographic variables

\begin{tabular}{|c|c|c|c|c|}
\hline \multirow[b]{2}{*}{ Variable } & \multicolumn{3}{|c|}{ Construct Group } & \multirow[b]{2}{*}{ p Value } \\
\hline & $\mathrm{HC}$ & SC & MC & \\
\hline Main curve, ${ }^{\circ}$ & $21.8 \pm 6.1$ & $22.8 \pm 8.3$ & $22.1 \pm 6.5$ & 0.821 \\
\hline Translation of main curve, $\mathrm{cm}$ & $14.2 \pm 8.8$ & $19.3 \pm 15.0$ & $18.7 \pm 12.7$ & 0.270 \\
\hline Curve correction of main curve, $\%$ & $63.0 \pm 9.4$ & $63.5 \pm 9.8$ & $61.8 \pm 11.9$ & 0.680 \\
\hline Proximal curve, ${ }^{\circ}$ & $12.6 \pm 6.2$ & $15.8 \pm 8.6$ & $16.0 \pm 7.3$ & 0.189 \\
\hline Thoracolumbar/lumbar curve, $^{\circ}$ & $17.5 \pm 6.0$ & $19.5 \pm 7.4$ & $18.2 \pm 6.1$ & 0.405 \\
\hline List, median (IQR), cm* & $1.3(1.0-1.7)$ & $1.6(0.8-2.4)$ & $1.8(0.8-3.1)$ & 0.567 \\
\hline $\mathrm{TK}^{\circ}$ & $23.1 \pm 6.3$ & $19.6 \pm 7.6$ & $23.4 \pm 6.9$ & 0.013 \\
\hline Kyphosis change, $^{\circ}$ & $-3.5 \pm 11.3$ & $-7.1 \pm 11.6$ & $0.1 \pm 10.9$ & 0.005 \\
\hline Proximal alignment at T2-5, ${ }^{\circ}$ & $15.0 \pm 5.7$ & $15.5 \pm 6.6$ & $14.1 \pm 6.9$ & 0.569 \\
\hline Thoracolumbar alignment at T10-L2, ${ }^{\circ}$ & $7.5 \pm 6.6$ & $7.0 \pm 5.7$ & $7.9 \pm 5.9$ & 0.728 \\
\hline Lumbar lordosis, ${ }^{\circ}$ & $58.9 \pm 11.2$ & $52.0 \pm 1.3$ & $55.0 \pm 11.0$ & 0.040 \\
\hline Sagittal vertical axis, median (IQR), $\mathrm{cm}^{*}$ & $2.7(1.2-4.5)$ & $2.9(1.7-5.2)$ & $3.0(1.6-5.0)$ & 0.923 \\
\hline
\end{tabular}

Values are presented as the mean \pm standard deviation unless otherwise specified. Boldface type indicates statistical significance.

* Absolute values are shown.

ance or proximal or thoracolumbar curve correction ( $\mathrm{p} \geq$ $0.189)$.

In the sagittal plane, the groups were similar at the preoperative stage, although lumbar lordosis was $65.4^{\circ} \pm$ $10.3^{\circ}$ in the $\mathrm{HC}$ group versus $58.9^{\circ} \pm 11.1^{\circ}$ and $61.0^{\circ} \pm$ $12.0^{\circ}$ in the SC and MC groups, respectively $(\mathrm{p}=0.067)$
(Table 1). Mean postoperative TK was $23.1^{\circ} \pm 6.3^{\circ}, 19.6^{\circ}$ $\pm 7.6^{\circ}$, and $23.4^{\circ} \pm 6.9^{\circ}$ in the $\mathrm{HC}, \mathrm{SC}$, and $\mathrm{MC}$ groups, respectively $(\mathrm{p}=0.013)$, and the mean change in TK was $-3.5^{\circ} \pm 11.3^{\circ},-7.1 \pm 11.6^{\circ}$, and $0.1^{\circ} \pm 10.9^{\circ}$, respectively (p $=0.005$ ) (Table 2 and Fig. 3). Post hoc analysis showed that the MC group had significantly higher postoperative

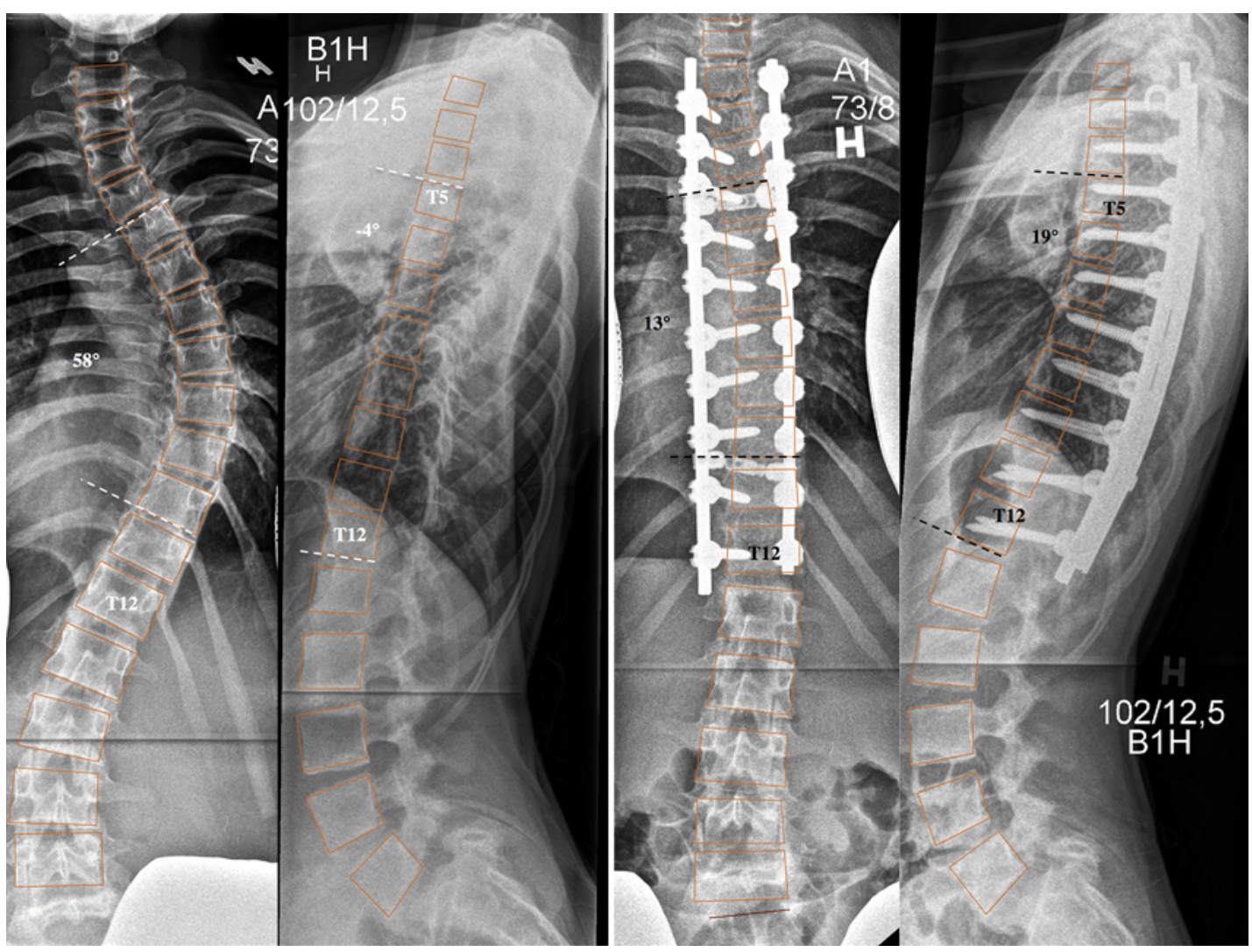

FIG. 2. AP and lateral radiographs of a Lenke Type $1 \mathrm{~A}$ curve instrumented with bilateral modified rods. Left: The preoperative main curve was $58^{\circ}$ with $-4^{\circ}$ TK. Right: Curve correction was $78 \%$, and TK was corrected to $19^{\circ}$ postoperatively. 

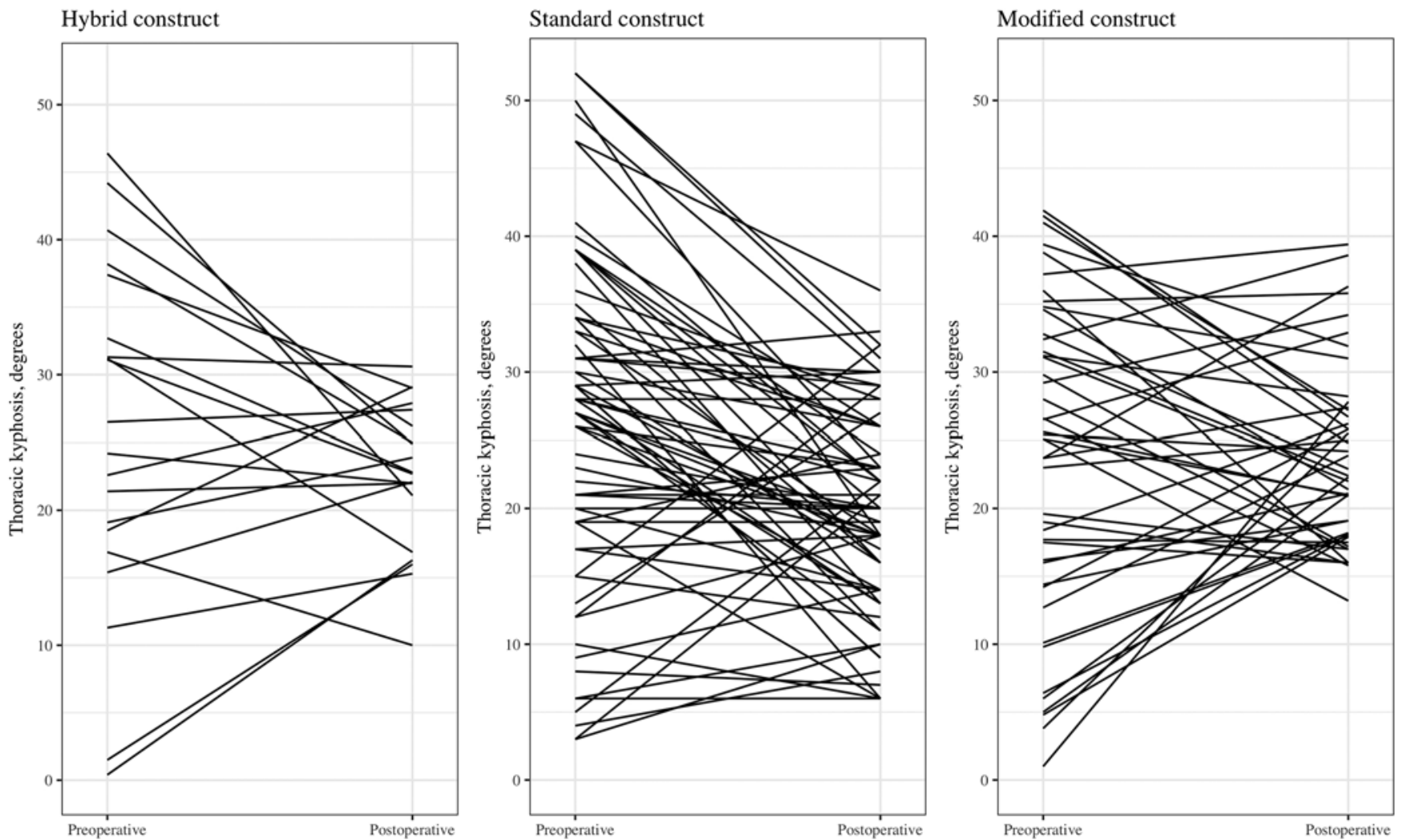

FIG. 3. Preoperative to postoperative changes in TK in the patients in each of the 3 groups. Four patients did not have sufficient preoperative and postoperative imaging and their cases are not illustrated.

TK and less loss of TK compared with the SC group ( $\mathrm{p} \leq$ 0.018 ) (Table 3). Postoperative $\mathrm{TK} \leq 10^{\circ}$ was found in 12 patients (17\%) in the SC group, 1 patient (5\%) in the $\mathrm{HC}$ group, and 1 patient $(2 \%)$ in the MC group $(\mathrm{p}=0.021)$ (Fig. 4). There was no significant correlation between coronal curve correction and kyphosis change (Pearson's $r=0.01$; $p=0.914)$, and there were no significant differences in proximal alignment, thoracolumbar alignment, or sagittal vertical alignment $(p \geq 0.249)$. Lumbar lordosis was $58.9^{\circ}$ $\pm 11.2^{\circ}$ in the $\mathrm{HC}$ group versus $52.0^{\circ} \pm 1.3^{\circ}$ and $55.0^{\circ} \pm$ $11.0^{\circ}$ in the SC and MC groups, respectively $(\mathrm{p}=0.040)$.

\section{Discussion}

The use of a MC improved the restoration of TK by more than $7^{\circ}$ compared with the SC group. A small loss of TK was observed in the $\mathrm{HC}$ group, which was not significantly different from the MC or SC group. Severe hypokyphosis $\left(\mathrm{TK} \leq 10^{\circ}\right)$ was found in only 1 patient in both the $\mathrm{HC}$ and MC groups versus 12 patients in the SC group. Fig. 3 shows that "normalization" occurred in the HC and $\mathrm{MC}$ groups in the sense that both large kyphosis and small kyphosis were corrected with surgery. However, in the SC group, a substantial number of patients with small preoperative TK had hypokyphosis after surgery. This is in line with previous results showing that with traditional PS instrumentation a smaller preoperative TK is the main driver of postoperative hypokyphosis. ${ }^{11,36}$

While PS instrumentation provides a strong 3-column fixation with considerable corrective power, it does have potential secondary effects in terms of imposed alignment (reduced postoperative spontaneous correction), distal and proximal junctional stress, and modifications in sagittal balance and spinopelvic alignment. ${ }^{30}$ Maintenance of the sagittal profile is a controversial topic, but a recent metaanalysis concluded that the PS construct had less power to restore TK compared to a hook-and-wire construct with caudal PS, ${ }^{5}$ although the coronal curve was not taken into account. The insertion and contouring of the rods has been suggested as the main factor that determines sagittal alignment, and it is commonly perceived that increas-

TABLE 3. Results of Tukey's post hoc test

\begin{tabular}{cc}
\hline Post Hoc Test & p Value \\
\hline TK & \\
\hline Standard vs hybrid & 0.118 \\
\hline Modified vs hybrid & 0.989 \\
\hline Modified vs standard & 0.018 \\
\hline Kyphosis change & \\
\hline Standard vs hybrid & 0.386 \\
\hline Modified vs hybrid & 0.473 \\
\hline Modified vs standard & $\mathbf{0 . 0 0 3}$ \\
\hline
\end{tabular}

Boldface type indicates statistical significance. 

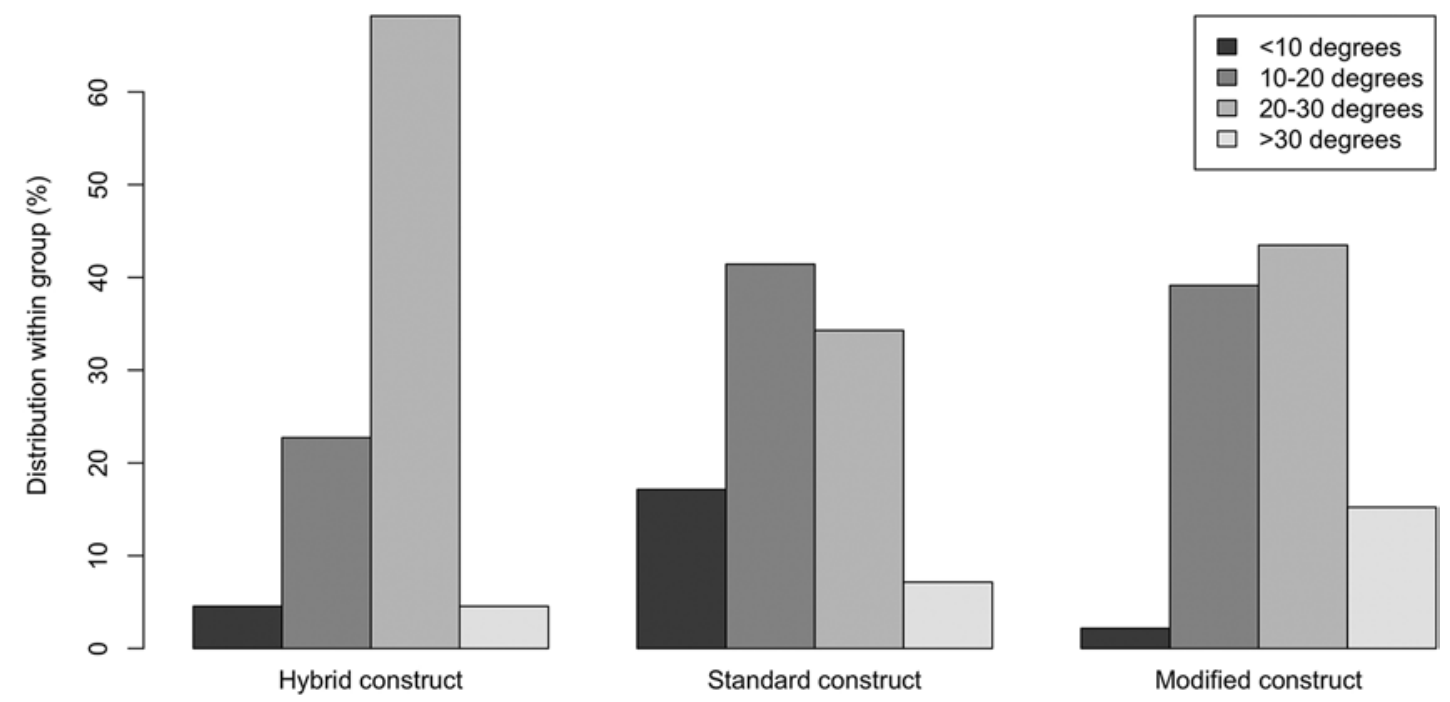

FIG. 4. Distribution of postoperative TK in the 3 groups.

ing rod strength reduces intraoperative flattening, thereby ensuring retention of the precontoured rod..$^{20,24}$ However, Prince et al. reviewed more than 1100 patients and found no evidence to suggest that increased rod strength improves TK. ${ }^{32}$ This was further underlined by Monazzam et al. who, in a multicenter review, showed no effect of rod strength in restoring $\mathrm{TK}^{28}$ but found that TK restoration relied primarily on surgical technique. Our results are in line with these findings showing that a technically less challenging construct ( $\mathrm{HC}$ or $\mathrm{MC}$ ) can improve postoperative alignment without compromising coronal curve correction.

Patients underwent standard AP and lateral radiography, and as such the current study does not provide assessment of axial plane rotation. In a recent study, Newton et al. used biplanar slot scanners (EOS) to visualize the 3D structure of the deformity. ${ }^{29}$ Newton et al. found that at the preoperative stage, TK is often overestimated on 2D radiographs and the difference between $2 \mathrm{D}$ and $3 \mathrm{D}$ TK measurements is strongly correlated with apical vertebral rotation. This, however was not the case for the postoperative assessment where the difference between the $2 \mathrm{D}$ and $3 \mathrm{D}$ radiographs was very small, likely due to surgical correction of rotation. As such, it is probable that the preoperative TK in the current study was smaller than reported and the actual loss of kyphosis was therefore overestimated. However, we would expect this variation to be distributed equally in all 3 groups, and the significant postoperative difference among groups was unlikely to be affected by apical rotation as this is largely corrected during surgery.

The clinical importance of reduced postoperative kyphosis has yet to be elucidated, and clinically relevant thresholds have not been established. The Lenke classification considers $\mathrm{TK}$ of $10^{\circ}-40^{\circ}$ to represent a normal range, ${ }^{23}$ while others consider TK of $10^{\circ}-20^{\circ}$ to be mild hypokyphosis. ${ }^{8,26}$ More than $25 \%$ of patients in all 3 groups of our study population had mild hypokyphosis according to this definition (Fig. 4), but, irrespective of the definitions, the long-term effect of postoperative hypokyphosis on patient-reported outcomes is still unknown. Postoperative hypokyphosis is unlikely to affect the patient's quality of life at early or midterm follow-up because AIS patients exhibit a range of compensatory mechanisms and rarely become decompensated., 2,3,22 However, in adult spinal deformity patients, several studies have shown that an optimal sagittal profile is essential to avoiding pain and disability, ${ }_{16,34}$ and, as such, a primary objective of AIS surgery should be to achieve an optimally aligned spine to ensure long-term quality of life.

Patients in the SC and MC groups were operated on at the same tertiary facility by a small dedicated group of surgeons, whereas patients in the HC group were operated on at a different facility by a single surgeon (J.A.I.F.). To ensure that our results were not affected by unrecognized differences in surgical technique, J.A.I.F. and M.G. performed several AIS procedures in conjunction prior to the initiation of the study. The homogeneity of the groups was further underlined by the similarities in the postoperative coronal parameters, including similar curve correction, global balance, and fusion length (Table 2). However, as with any multicenter study, our results are potentially influenced by local differences in surgical factors, which is a limitation to our study.

The clinical use of a differentially shaped rod with a reduced proximal diameter has not been previously described. As such, this study was designed as a proof of concept and 2-year follow-up data are not included, which is a limitation to the clinical applicability of our findings. Previous studies have shown that TK remains stable after PS instrumentation, but a small increase $\left(0^{\circ}-4^{\circ}\right)$ can be expected after 2 years. ${ }^{6,18,19}$ The lack of midterm followup data does not, however, affect the biomechanical interpretation of our findings, and our data support the notion that a modified rod construct with a diameter transition can improve sagittal alignment after surgical treatment of AIS. Although the BR design is not universally used, we hypothesize that the principles of the diameter transition 
rod can be transferred to other designs, and we would encourage future studies to verify this assumption.

\section{Conclusions}

In the 3 rod constructs with different rigidity profiles, we found significantly better restoration of kyphosis with the use of bilateral modified rods compared with bilateral standard rods. In the MC and $\mathrm{HC}$ groups, the rate of severe postoperative hypokyphosis was significantly lower than in the SC group. This is the first study to describe the clinical use of a rod with a reduced proximal diameter and show marked radiographic improvement in sagittal alignment. Future studies should address the long-term clinical implications of this improvement.

\section{References}

1. Angelliaume A, Ferrero E, Mazda K, Le Hanneur M, Accabled F, de Gauzy JS, et al: Titanium vs cobalt chromium: what is the best rod material to enhance adolescent idiopathic scoliosis correction with sublaminar bands? Eur Spine J 26:1732-1738, 2017

2. Arlet V, Ouellet JA, Shilt J, Shen FH, Wood K, Chan D, et al: Subjective evaluation of treatment outcomes of instrumentation with pedicle screws or hybrid constructs in Lenke Type 1 and 2 adolescent idiopathic scoliosis: what happens when judges are blinded to the instrumentation? Eur Spine J 18:1927-1935, 2009

3. Bennett JT, Hoashi JS, Ames RJ, Kimball JS, Pahys JM, Samdani AF: The posterior pedicle screw construct: 5-year results for thoracolumbar and lumbar curves. J Neurosurg Spine 19:658-663, 2013

4. Cahill PJ, Wang W, Asghar J, Booker R, Betz RR, Ramsey C, et al: The use of a transition rod may prevent proximal junctional kyphosis in the thoracic spine after scoliosis surgery: a finite element analysis. Spine (Phila Pa 1976) 37:E687E695, 2012

5. Cao Y, Xiong W, Li F: Pedicle screw versus hybrid construct instrumentation in adolescent idiopathic scoliosis: meta-analysis of thoracic kyphosis. Spine (Phila Pa 1976) 39:E800 E810, 2014

6. Cheng I, Kim Y, Gupta MC, Bridwell KH, Hurford RK, Lee SS, et al: Apical sublaminar wires versus pedicle screwswhich provides better results for surgical correction of adolescent idiopathic scoliosis? Spine (Phila Pa 1976) 30:21042112,2005

7. Clement JL, Chau E, Kimkpe C, Vallade MJ: Restoration of thoracic kyphosis by posterior instrumentation in adolescent idiopathic scoliosis: comparative radiographic analysis of two methods of reduction. Spine (Phila Pa 1976) 33:1579-1587, 2008

8. Clément JL, Geoffray A, Yagoubi F, Chau E, Solla F, Oborocianu I, et al: Relationship between thoracic hypokyphosis, lumbar lordosis and sagittal pelvic parameters in adolescent idiopathic scoliosis. Eur Spine J 22:2414-2420, 2013

9. Crawford AH, Lykissas MG, Gao X, Eismann E, Anadio J: All-pedicle screw versus hybrid instrumentation in adolescent idiopathic scoliosis surgery: a comparative radiographical study with a minimum 2-year follow-up. Spine (Phila Pa 1976) 38:1199-1208, 2013

10. de Kleuver M, Lewis SJ, Germscheid NM, Kamper SJ, Alanay A, Berven SH, et al: Optimal surgical care for adolescent idiopathic scoliosis: an international consensus. Eur Spine J 23:2603-2618, 2014

11. Fletcher ND, Hopkins J, McClung A, Browne R, Sucato DJ: Residual thoracic hypokyphosis after posterior spinal fusion and instrumentation in adolescent idiopathic scoliosis: risk factors and clinical ramifications. Spine (Phila Pa 1976) 37:200-206, 2012

12. Gehrchen M, Ohrt-Nissen S, Hallager DW, Dahl B: A uniquely shaped rod improves curve correction in surgical treatment of adolescent idiopathic scoliosis. Spine (Phila Pa 1976) 41:1139-1145, 2016

13. Ghandehari H, Mahabadi MA, Mahdavi SM, Shahsavaripour A, Seyed Tari HV, Safdari F: Evaluation of patient outcome and satisfaction after surgical treatment of adolescent idiopathic scoliosis using Scoliosis Research Society-30. Arch Bone Jt Surg 3:109-113, 2015

14. Glassman SD, Bridwell K, Dimar JR, Horton W, Berven S, Schwab F: The impact of positive sagittal balance in adult spinal deformity. Spine (Phila Pa 1976) 30:2024-2029, 2005

15. Haher TR, Gorup JM, Shin TM, Homel P, Merola AA, Grogan DP, et al: Results of the Scoliosis Research Society instrument for evaluation of surgical outcome in adolescent idiopathic scoliosis. A multicenter study of 244 patients. Spine (Phila Pa 1976) 24:1435-1440, 1999

16. Hallager DW, Hansen LV, Dragsted CR, Peytz N, Gehrchen M, Dahl B: A comprehensive analysis of the SRS-Schwab Adult Spinal Deformity Classification and confounding variables: a prospective, non-US cross-sectional study in 292 patients. Spine (Phila Pa 1976) 41:E589-E597, 2016

17. Hwang SW, Samdani AF, Gressot LV, Hubler K, Marks MC, Bastrom TP, et al: Effect of direct vertebral body derotation on the sagittal profile in adolescent idiopathic scoliosis. Eur Spine J 21:31-39, 2012

18. Hwang SW, Samdani AF, Wormser B, Amin H, Kimball JS, Ames RJ, et al: Comparison of 5-year outcomes between pedicle screw and hybrid constructs in adolescent idiopathic scoliosis. J Neurosurg Spine (Phila Pa 1976) 17:212-219, 2012

19. Kim YJ, Lenke LG, Kim J, Bridwell KH, Cho SK, Cheh G, et al: Comparative analysis of pedicle screw versus hybrid instrumentation in posterior spinal fusion of adolescent idiopathic scoliosis. Spine (Phila Pa 1976) 31:291-298, 2006

20. Lamerain M, Bachy M, Delpont M, Kabbaj R, Mary P, Vialle $\mathrm{R}$ : $\mathrm{CoCr}$ rods provide better frontal correction of adolescent idiopathic scoliosis treated by all-pedicle screw fixation. Eur Spine J 23:1190-1196, 2014

21. Ledonio CGT, Polly DW Jr, Vitale MG, Wang Q, Richards BS: Pediatric pedicle screws: comparative effectiveness and safety: a systematic literature review from the Scoliosis Research Society and the Pediatric Orthopaedic Society of North America task force. J Bone Joint Surg Am 93:12271234,2011

22. Legarreta CA, Barrios C, Rositto GE, Reviriego JM, Maruenda JI, Escalada MN, et al: Cervical and thoracic sagittal misalignment after surgery for adolescent idiopathic scoliosis: a comparative study of all pedicle screws versus hybrid instrumentation. Spine (Phila Pa 1976) 39:1330-1337, 2014

23. Lenke LG, Betz RR, Harms J, Bridwell KH, Clements DH, Lowe TG, et al: Adolescent idiopathic scoliosis: a new classification to determine extent of spinal arthrodesis. J Bone Joint Surg Am 83-A:1169-1181, 2001

24. Liu H, Li Z, Li S, Zhang K, Yang H, Wang J, et al: Main thoracic curve adolescent idiopathic scoliosis: association of higher rod stiffness and concave-side pedicle screw density with improvement in sagittal thoracic kyphosis restoration. J Neurosurg Spine 22:259-266, 2015

25. Lowenstein JE, Matsumoto H, Vitale MG, Weidenbaum M, Gomez JA, Lee FY, et al: Coronal and sagittal plane correction in adolescent idiopathic scoliosis: a comparison between all pedicle screw versus hybrid thoracic hook lumbar screw constructs. Spine (Phila Pa 1976) 32:448-452, 2007

26. Luk KDK, Vidyadhara S, Lu DS, Wong YW, Cheung WY, Cheung KMC: Coupling between sagittal and frontal plane 
deformity correction in idiopathic thoracic scoliosis and its relationship with postoperative sagittal alignment. Spine (Phila Pa 1976) 35:1158-1164, 2010

27. Mladenov KV, Vaeterlein C, Stuecker R: Selective posterior thoracic fusion by means of direct vertebral derotation in adolescent idiopathic scoliosis: effects on the sagittal alignment. Eur Spine J 20:1114-1117, 2011

28. Monazzam S, Newton PO, Bastrom TP, Yaszay B, Roaf R, Dickson RA, et al: Multicenter comparison of the factors important in restoring thoracic kyphosis during posterior instrumentation for adolescent idiopathic scoliosis. Spine Deform 1:359-364, 2013

29. Newton PO, Fujimori T, Doan J, Reighard FG, Bastrom TP, Misaghi A: Defining the "three-dimensional sagittal plane" in thoracic adolescent idiopathic scoliosis. J Bone Joint Surg Am 97:1694-1701, 2015

30. Newton PO, O'Brien MF, Shufflebarger HL, Betz RR, Dickson RA, Harms J: Idiopathic Scoliosis. The Harms Study Group Treatment Guide. New York: Thieme, 2010

31. Ng BK, Chau WW, Hui CN, Cheng PY, Wong CY, Wang B, et al: HRQoL assessment by SRS-30 for Chinese patients with surgery for Adolescent Idiopathic Scoliosis (AIS). Scoliosis 10 (Suppl 2):S19, 2015

32. Prince DE, Matsumoto H, Chan CM, Gomez JA, Hyman JE, Roye DP Jr, et al: The effect of rod diameter on correction of adolescent idiopathic scoliosis at two years follow-up. J Pediatr Orthop 34:22-28, 2014

33. Rose PS, Lenke LG, Bridwell KH, Mulconrey DS, Cronen GA, Buchowski JM, et al: Pedicle screw instrumentation for adult idiopathic scoliosis: an improvement over hook/hybrid fixation. Spine (Phila Pa 1976) 34:852-858, 2009

34. Roussouly P, Nnadi C: Sagittal plane deformity: an overview of interpretation and management. Eur Spine J 19:18241836,2010

35. Rushton PRP, Grevitt MP: What is the effect of surgery on the quality of life of the adolescent with adolescent idiopathic scoliosis? A review and statistical analysis of the literature. Spine (Phila Pa 1976) 38:786-794, 2013

36. Sarwahi V, Wollowick AL, Kulkarni PM, Amaral TD: Ped- icle screws allow maintenance of thoracic kyphosis in AIS, but ability to improve hypokyphosis is limited. Spine J 14 (11 Suppl):154S, 2014 (Abstract)

37. Sudo H, Ito M, Abe Y, Abumi K, Takahata M, Nagahama $\mathrm{K}$, et al: Surgical treatment of Lenke 1 thoracic adolescent idiopathic scoliosis with maintenance of kyphosis using the simultaneous double-rod rotation technique. Spine (Phila Pa 1976) 39:1163-1169, 2014

38. Yilmaz G, Borkhuu B, Dhawale AA, Oto M, Littleton AG, Mason DE, et al: Comparative analysis of hook, hybrid, and pedicle screw instrumentation in the posterior treatment of adolescent idiopathic scoliosis. J Pediatr Orthop 32:490499, 2012

\section{Disclosures}

Drs. Ohrt-Nissen, Gehrchen, and Dahl received an institutional grant from K2M unrelated to the submitted work. Drs. Gehrchen and Dahl received an institutional grant from Medtronic unrelated to the submitted work. Dr. Ferguson is a consultant for K2M and has a nonfinancial relationship with SRS.

\section{Author Contributions}

Conception and design: all authors. Acquisition of data: Ohrt-Nissen, Dragsted. Analysis and interpretation of data: Ohrt-Nissen, Gehrchen. Drafting the article: Ohrt-Nissen. Critically revising the article: all authors. Reviewed submitted version of manuscript: Ohrt-Nissen, Dragsted, Dahl, Gehrchen. Approved the final version of the manuscript on behalf of all authors: Ohrt-Nissen. Statistical analysis: Ohrt-Nissen. Administrative/technical/material support: Ferguson, Gehrchen. Study supervision: Dahl, Ferguson, Gehrchen.

\section{Correspondence}

Søren Ohrt-Nissen, Department of Orthopedic Surgery, Rigshospitalet, Blegdamsvej 9, Copenhagen East 2100, Denmark. email: ohrtnissen@gmail.com. 